\title{
Impact of adult sons' marriage squeeze on the mental health of parents in rural China
}

\author{
Guangyan Chen ${ }^{1}$ (D) Wei Si $^{*}$ (D) Lingling Qiu $^{2} \mathbb{D}$ \\ ${ }^{1}$ College of Economics and Management, China Agricultural University, 100083, Beijing, China. E-mail: 836818739@qq.com. \\ "Corresponding author. \\ ${ }^{2}$ Graduate Department of Forestry, University of Toronto, Toronto, Ontario, Canada. \\ ABSTRACT: Studying the influencing factors and interventions of mental health in rural China has important practical significance for \\ promoting personal development and social progress. Using the 2016 waves of the China Family Panel Studies data, this paper examined \\ the effect of adult sons' marriage squeeze on parents' mental health in rural China and its corresponding mechanisms. Our study showed a \\ significant negative association between adult sons' marriage squeeze and the mental health status of rural parents. Moreover, the negative \\ association of adult sons' marriage squeeze with mental health is larger for female parents, parents who are less than 60 years old and parents \\ living with children. In addition, we investigated possible mechanisms of the effect, including intergenerational support, intergenerational \\ relationship and neighborhood relationship, and that adult sons' marriage squeeze mainly damages the mental health of rural parents by \\ increasing the downstream intergenerational support of rural parents and worsening intergenerational and neighborhood relationships. \\ Key words: adult son, marriage squeeze, mental health, rural parent.
}

Impacto do casamento dos filhos adultos na saúde mental dos pais na China rural

\begin{abstract}
RESUMO: $O$ estudo dos fatores e intervenções de saúde mental na China rural tem um significado prático importante para promover o desenvolvimento pessoal e o progresso social. Usando dados de 2016 provenientes do China Family Panel Studies (CFPS), este artigo estudou o efeito do "aperto do casamento" de um filho adulto, na saúde mental dos pais, na zona rural da China e seus mecanismos correspondentes. $O$ termo aperto do casamento refere-se a um desequilibrio entre o número de homens e mulheres disponíveis para se casar em uma determinada sociedade. Nesse estudo evidencia-se uma associação significativamente negativa entre o "aperto no casamento" do filho adulto e o estado de saúde mental dos pais rurais. Além disso, a associação negativa do "aperto do casamento" de um filho adulto com a saúde mental é maior para mães, pais com menos de 60 anos e pais que vivem com filhos. Além disso, investigamos possiveis efeitos, incluindo apoio intergeracional, relacionamento intergeracional e relacionamento de vizinhança, e descobrimos que o aperto do casamento do filho adulto prejudica principalmente a saúde mental dos pais rurais, aumentando o apoio intergeracional e piorando relações intergeracionais e de vizinhança.
\end{abstract}

Palavras-chave: filho adulto, aperto no casamento, saúde mental, familia rural.

\section{INTRODUCTION}

As the proverb goes, "The body is the capital of revolution", which means maintaining wellbeing is a prerequisite for an individual to achieve his or her self-value and happiness. According to the World Health Organization's definition of health, human health does not simply refer to physical health, it includes mental health as well. Therefore, mental health and physical health are of equal importance to human beings. However, due to limitations of objective conditions and personal cognition, we tend to pay more attention to the physical health, and neglect people's mental health. In fact, in modern China, especially in rural China, mental health issues have become salient public health issues and prominent social issues, which we must take seriously. Conversely, with the rapid rural population migration and its accompanying social structure changes, the prevalence of mental illness among rural Chinese people has continued to rise. According to China National Mental Health 
Development Report (2017-2018), about 20.9\% of people in rural China suffered from severe mental illness in 2017. And currently, this ratio is still increasing. Conversely, the total socio-economic cost caused by mental health disorders in rural China is incredibly high. Firstly, the treatment of mental illness will increase the burden of living for rural residents and squeeze out funds that should be used to improve rural residents' welfare and agricultural production (XIAO et al., 2016). Secondly, mental illness will significantly reduce farmers' agricultural production participation rate and reduce participants' agricultural production efficiency and their income level (LIAO \& SONG, 2013; GAO et al., 2018). Thirdly, mental illness has become an important factor of the instability of rural society, such as fighting, suicide, and crime (LIU et al., 2017). Therefore, studying the influencing factors and interventions of rural Chinese people's mental health at this stage has important practical significance for promoting personal development and social progress.

Existing studies are mainly focused on examining the factors affecting rural Chinese people's mental health, such as demographic characteristics including age, gender, marriage, education, etc. (ZHANG \& LI, 2018; CHEN \& CHEN, 2012), socioeconomic status (REN et al., 2016; GUO et al., 2019), social support (TAO \& SHEN, 2014; XU, 2018) and body type (LI et al., 2004; ZHANG et al., 2016). However, little attention has been paid to the role of adult children's marriage, especially the marriage squeeze of adult sons caused by a serious gender imbalance in middle aged and elderly people's mental health in rural China. In fact, marriage squeeze of adult sons may be an important factor affecting mental health of rural middle aged and elderly people, as it may have an impact on family relationship, intergenerational succession and parental pension (GUO \& JIN, 2012). What's more, most middle aged and elderly Chinese parents who are influenced by traditional Confucian culture consider their sons' marriage as their major life responsibility. In this regard, rural parents are painstaking to help their sons find suitable women for marriage purpose, some of whom even take this responsibility more seriously than the existence of their own life (SUN, 2005; WEI \& ZHANG, 2011). Thus, when some rural parents are unable to see their older adult sons' marriage, they are most likely to bear a psychological burden of anxiety, guilt, and self-blame. And they also tend to be discriminated by their neighbors (LI \& LI, 2008), which may further increase their psychological burden due to their inability to fulfill the assumed mission that a Chinese parent should achieve. In a word, rural middle aged and elderly parent's mental health is thus likely to be negatively affected by adult sons' marriage squeeze. Therefore, it is important to test the relationship between marital status of older adult sons and mental health of their parents in rural China.

The goal of this study is to examine the relationship between adult sons' marriage squeeze and the mental health of middle aged and elderly parents in rural China. In order to achieve this research goal, we examined the overall association between adult sons' marriage squeeze and the mental health of rural middle aged and elderly parents by using a nationally representative dataset, and then explored the heterogeneity and mechanisms of associations between adult sons' marriage squeeze and rural parents' mental health. Specifically, we measured differences in the effects by rural parents' gender, age, and living arrangement. Quantile regression methods were used to explore the heterogeneous associations between adult sons' marriage squeeze and different levels of rural parents'mental health. We also examined three channels through which adult sons' marriage squeeze may affect the mental health of their parents, which are respectively intergenerational support, intergenerational relationship, and neighborhood relationship. Finally, we used a subsample including one-child families and two-children families and two stage least squares (2SLS) regression method with instrumental variables (IV) to address the potential endogeneity in our empirical analyses and check the robustness of our findings.

The rest of the paper is organized as follows: Section 2 describes the data and main variables; Section 3 introduces the methodology; Section 4 presents our results of relationships between adult sons' marriage squeeze and their rural parent's mental health. We also examined the mechanisms of the association between adult sons' marriage squeeze and their rural parent's mental health (namely, intergenerational support, intergenerational relationship and neighborhood relationship); Section 5 is the discussion and conclusion.

\section{DATA}

\section{Data source and sampling}

Data used in this paper are obtained from the China Family panel Studies data (CFPS) for the years of 2014 and 2016, which has been organized and implemented by the China Social Science Research Center of Peking University. It aims to collect a set of micro-data on households that are representative of people aged 10 years old and older in China. The CFPS is a nationally representative 
longitudinal survey, covering 25 of the 31 provinces in mainland China, and accounting for $95 \%$ of the national population (XIE, 2012). The CFPS survey began in 2010 and has gone through three follow-up surveys in 2012, 2014 and 2016. In 2010, the baseline survey interviewed 57200 respondents from 19986 households in 162 counties, selected using random sampling methods with probability proportional to size (PPS). The questionnaire survey is composed of the social characteristics of the respondents, and their family background, economic status, health status, lifestyle and community situation, providing important data support for this paper to explore the impact of adult sons' marriage squeeze on parental mental health in rural China.

The selected sample for our study includes people aged from 45 through 92 in rural China, who have at least one alive adult son aged 28 years old and over. When removing individuals with missing values and outliers, the study sample consis of 3585 observations.

\section{Dependent variables}

The dependent variable in this study is rural parents' mental health. We assess rural parents' mental health by using the Center for Epidemiologic Studies Depression Scale (CESD). The CESD scale originally have 20 items. As values of some items are missing, this paper uses a simplified CESD profile consisting of 8 items. The simplified CESD profile contains 2 physical symptom items, 4 depression emotional items, and 2 positive emotional items. Each item requires the respondent to offer comments on their feelings and behaviors for the past week, given four choices including "nearly ( $<1$ days)", "sometimes (1-2 days)", "often (3-4 days)" and the "most of the time (5-7 days)", which are numbered as 1, 2, 3, 4 respectively. Therefore, the total CESD score ranges from 8 to 32 . The higher the CESD score, the worse the mental health of the interviewed respondents; The smaller the CESD score, the better the mental health of the interviewed respondents.

\section{Independent variables \\ Adult sons' marriage squeeze}

The key independent variable in this paper is adult sons' marriage squeeze. Referring to the study of GUO \& JIN (2012), we test two different measures of adult sons' marriage squeeze, including a dummy variable indicating whether interviewees have unmarried sons aged 28 years old and over (1 $=$ yes, $0=$ no), and an integer count of the number of unmarried sons aged 28 years old and over. According to the CFPS family relationship questionnaire, this paper selects samples of all middle-aged and elderly people with adult sons aged 28 years old and over. In these samples, if the middle-aged and elderly people surveyed have at least one son who is 28 years old and over (not attending school) and has not married, the value for whether interviewees have unmarried sons aged 28 years old and over is 1 . Otherwise, the value will be 0 . Theoretically, the more unmarried sons rural parents have, the greater psychological pressure they will bear. This number of unmarried sons aged 28 years old and above variable; therefore, can capture a 'dose' effect of the amount of adult sons' marriage squeeze.

\section{Control variables}

Prior researches have shown that various factors may correlate with parent's mental health (YIN et al., 2018; YE \& CHEN, 2014; Zhou et al., 2018). Accordingly, we includes characteristics of rural parents, family, and regions as control variables. Parent's characteristic variables includes age (in years), gender $(0=$ female, $1=$ male $)$, education (1=illiterate, 2=primary School, 3=junior high school, 4=senior high school, 5=3-Year College, 6=4year college and above $)$, marital status $(0=$ unmarried, $1=$ married), lagging self-evaluation of physical health ( $1=$ excellent, $2=$ very good, $3=$ good, 4=fair, $5=$ poor $)$, personal relative income level $(1=$ very low, 2=low, 3=fair, 4=high, 5=very high) and whether having medical insurance $(1=y e s, 0=n o)$. Family characteristic variables are the number of adult children, living arrangement (1=living with children, $0=$ living alone or only living with the spouse) and housing conditions (The housing conditions consist of four items: the degree of overcrowding, the degree of interior decoration, the degree of indoor cleanliness and the furnishings. Each item consists of 1-7 scores, the larger the score, the better the situation. Therefore, the total housing condition score is range from 4 to 28.). Region characteristic variables are public facility's status and ecological environment of the community ( $1=$ very good, $2=$ good, $3=$ fair, $4=$ Poor, $5=$ very poor). In addition, considering that there may be differences in the situation of older adult sons unmarried in different regions (provinces), this paper also controls the provincial variables.

\section{Descriptive statistics}

Table 1 presents descriptive statistics for the total sample. For the dependent variable, the average CESD score is 14.135 , indicating that there are relatively few rural parents with severe 
Table 1 - Descriptive statistics of variables.

\begin{tabular}{|c|c|c|c|c|c|}
\hline Variable & Obs & Mean & Std. Dev. & Min & Max \\
\hline CESD & 3585 & 14.135 & 4.480 & 8 & 32 \\
\hline Whether having unmarried sons aged 28 years old and above in 2016 & 3585 & 0.178 & 0.383 & 0 & 1 \\
\hline Whether having unmarried sons aged 28 years old and above in 2014 & 3585 & 0.205 & 0.404 & 0 & 1 \\
\hline The number of unmarried sons aged 28 years old and above in 2016 & 3585 & 0.198 & 0.445 & 0 & 3 \\
\hline The number of unmarried sons aged 28 years old and above in 2014 & 3585 & 0.229 & 0.481 & 0 & 4 \\
\hline Age & 3585 & 64.232 & 8.042 & 45 & 96 \\
\hline Gender & 3585 & 0.451 & 0.498 & 0 & 1 \\
\hline Education & 3585 & 1.714 & 0.964 & 1 & 6 \\
\hline Marital status & 3585 & 0.818 & 0.386 & 0 & 1 \\
\hline Lagging self-evaluation of physical health & 3585 & 3.456 & 1.265 & 1 & 5 \\
\hline Personal relative income level & 3585 & 2.462 & 1.154 & 1 & 5 \\
\hline Whether having medical insurance & 3585 & 0.953 & 0.213 & 0 & 1 \\
\hline The number of adult children & 3585 & 1.372 & 0.656 & 1 & 7 \\
\hline Living arrangement & 3585 & 0.617 & 0.486 & 0 & 1 \\
\hline Housing conditions & 3585 & 16.581 & 4.627 & 4 & 28 \\
\hline Public facility's status of the community & 3585 & 2.610 & 0.935 & 1 & 5 \\
\hline Ecological environment of the community & 3585 & 2.658 & 0.952 & 1 & 5 \\
\hline
\end{tabular}

mental illness. For the key independent variable, the mean value of whether having unmarried sons aged 28 years old and above in 2016 and in 2014 are respectively 0.178 and 0.205 , showing that there is a relatively large proportion of older sons who are squeezed by marriage. In addition, the mean value of the number of unmarried sons aged 28 years old and above in 2016 and in 2014 further indicates that there are fewer families with multiple unmarried sons aged 28 years old and above. That is, in families having older unmarried sons, the number of unmarried sons mainly consists of one person.

In terms of control variables, the average age is 64.232 years old. Females account for approximately half of the sample $(45.1 \%)$. Most of the respondents haven't completed primary school education, as the mean value of education is 1.714 . More than half of the respondents are married and presently live with the spouse $(0.818)$. The mean value of lagging self-evaluation of physical health is 3.456, indicating that rural parent's physical health is relatively poor. And most rural parents have lower income levels. At present, a majority of respondents have medical insurance. The number of adult children is mainly below 2 in the family. The proportion of parents living with children accounts for $61.7 \%$. The living conditions of residents are mostly at a general level. Table 1 also shows that the mean value of public facility's status and ecological environment of the community are respectively 2.610 and 2.658, indicating that rural basic infrastructure and ecological environment are relatively poor in rural areas.

\section{METHODOLOGY}

\section{Ordinary least squares regression}

We examines the association of adult sons' marriage squeeze with rural parent's mental health by using an Ordinary Least Squares Regression framework in this section. The basic linear rural parent's mental health production function is specified as follows:

$Y=a_{0}+a_{1} \mathrm{ASMS}+\mathrm{a}_{2} \mathrm{X}+\varepsilon$

Where $Y$ is the dependent variable, in this paper this refers to the CESD score of rural parent; $A S M S$ is the key independent variable, which are represented by whether having unmarried sons aged 28 years old and above and the number of unmarried sons aged 28 years old and above, respectively; $X$ represents other control variables, including rural parent's age, gender, education, marital status, lagging selfevaluation of physical health, personal relative income level, whether having medical insurance, the number of adult children, living arrangement, housing conditions, public facilities status, ecological environment of the community and province. $\alpha_{1}$ and $\alpha_{2}$ are regression coefficients. And $\varepsilon$ is the random error term. 
Two stage least square regression with instrumental variable method (IV-2SLS)

Considering that older adult sons' marriage behavior does not satisfy the randomness of sampling, and there may be "self-selection". That is, rural middle-aged and elderly parent with 28-yearold and above unmarried adult son and those who do not, may have systematic differences in the level of self-features. In addition, there may be a causal relationship between the marriage squeeze of adult sons and the mental health of their parents in rural China. So, our estimated results may be selective biases if we directly perform regression between adult sons' marriage squeeze and their rural parents' mental health.

Since the Two-stage least square regression with Instrumental variable method (2SLS-IV) can effectively control the estimation bias caused by selfselection and mutual causality. This paper intends to use the IV-2SLS method to reexamine the impact of adult sons' marriage squeeze on rural parental mental health. The expression of the IV-2SLS method is as follows:

$$
\begin{aligned}
& A S M S=\beta_{1}+\beta_{2} I V+\beta_{3} X+\mu \\
& Y=y_{0}+y_{1} \widehat{A S M S}+y_{2} X+\varepsilon
\end{aligned}
$$

Where, formula (2) is the estimation equation of the first stage. And the IV is the selected instrumental variable, which is represented by "The proportion of families with unmarried sons aged 28 years old and above in the community". Equation (3) is the estimation equation of the second stage, and $\widehat{A S M S}$ is the predicted value of $A S M S$ in equation (2). The rest of the variables have the same meaning as equation (1). The premise of 2SLS effective estimation is that there are endogenous explanatory variable and the selected instrument variables is reasonable. Therefore, we use the Wu-Hausman test and the Wald F-statistics based on the KleibergenPaap statistic to test whether there is an endogenous explanatory variable and whether the selected instrument variable is suitable, respectively (As there is only one instrumental variable in this paper, do the over-identification test is not performed).

\section{EMPIRICAL RESULTS AND ANALYSES}

\section{Adult sons' marriage squeeze and rural parent's mental health}

Table 2 presents the estimated results of the association of adult sons' marriage squeeze and rural parent's mental health under two specifications across two years. Columns (1) and (2) report the estimation results indicating the impact of adult sons' marriage squeeze on the mental health of rural parents, using data in the year of 2016. Similarly, columns (3) and (4) report the estimatin results using data in the year of 2014. In colums (1) and (3), adult sons' marriage squeeze is represented by the discrete variable "whether having unmarried sons aged 28 years old and above"; In columns (2) and (4), adult sons' marriage squeeze is represented by the continuous variable "the number of unmarried sons aged 28 years old and above". In order to test for heteroscedasticity, Breusch-Pagen test is performed for each of the four equations. Results indicate that heteroscedasticity exists in those four equations. Therefore, in the OLS estimation process, instead of regular standard errors, robust standard errors are used to address the heteroscedasticity problem (Breusch-Pagan test is also performed in each of the model estimations below wherever it is applicable.) Control variables and provincial variable are included in all models, and Huber-White robust standard errors are reported in parentheses. The estimated results in column (1) to column (2) show a significant negative association between adult sons' marriage squeeze and rural parent's mental health. More specifically, rural parent that has unmarried adult sons aged 28 years old and above is associated with 0.061 standard deviation of CESD score growth. In addition, rural parent with more unmarried sons aged 28 years old and above are associated with worse mental health status. For control variables, the mother's CESD score is significantly higher than father. Education, marital status, personal income level, whether having medical insurance, living arrangement, housing conditions are negatively associated with rural parent's CESD score. And lagging self-evaluation of physical health, public facility's status and ecological environment of the community can positively affect rural parental mental health.

Further, in column (3) to column (4), we respectively use, whether having unmarried adult sons aged 28 years old and above in 2014 and the number of unmarried sons aged 28 years old and above in 2014 as the independent variables to better understand the effect size of the adult sons' marriage squeeze on mental health status of rural parents, because adult sons' marriage squeeze and parents' mental health in the same year may have a causal relationship. The estimates demonstrate that the average CESD score of rural parents who have adult unmarried sons aged 28 years old and above are 0.046 higher than their counterparts who have no adult unmarried sons aged 28 years old and 
Table 2 - Ordinary Least Squares estimate of the relationships between adult sons' marriage squeeze in 2016 and in 2014 and their rural parental mental health in 2016.

\begin{tabular}{|c|c|c|c|c|}
\hline Variables & $(1)$ & $(2)$ & (3) & (4) \\
\hline & 2016 & 2016 & 2014 & 2014 \\
\hline \multirow{2}{*}{ Whether having unmarried sons aged 28 years old and above $(1=$ yes, $0=$ no $)$} & $0.061^{* * *}$ & & $0.046^{* * *}$ & \\
\hline & $(0.013)$ & & $(0.012)$ & \\
\hline \multirow{2}{*}{ The number of unmarried sons aged 28 years old and above } & & $0.051^{* * *}$ & & $0.031^{* * *}$ \\
\hline & & $(0.011)$ & & $(0.010)$ \\
\hline \multirow[b]{2}{*}{ Age } & 0.000 & 0.001 & 0.001 & 0.001 \\
\hline & $(0.001)$ & $(0.001)$ & $(0.001)$ & $(0.001)$ \\
\hline \multirow{2}{*}{ Gender } & $-0.060^{* * *}$ & $-0.059^{* * *}$ & $-0.060^{* * *}$ & $-0.060^{* * *}$ \\
\hline & $(0.010)$ & $(0.010)$ & $(0.010)$ & $(0.010)$ \\
\hline \multirow{2}{*}{ Education } & $-0.027^{* * *}$ & $-0.027^{* * *}$ & $-0.028^{* * *}$ & $-0.028^{* * *}$ \\
\hline & $(0.005)$ & $(0.005)$ & $(0.005)$ & $(0.005)$ \\
\hline \multirow{2}{*}{ Marital status } & $-0.090^{* * *}$ & $-0.090^{* * *}$ & $-0.090^{* * *}$ & $-0.090^{* * *}$ \\
\hline & $(0.014)$ & $(0.014)$ & $(0.014)$ & $(0.014)$ \\
\hline \multirow{2}{*}{ Lagging self-evaluation of physical health } & $0.055^{* * *}$ & $0.055^{* * *}$ & $0.055^{* * *}$ & $0.055^{* * *}$ \\
\hline & $(0.004)$ & $(0.004)$ & $(0.004)$ & $(0.004)$ \\
\hline \multirow{2}{*}{ Personal relative income level } & $-0.023^{* * *}$ & $-0.023^{* * *}$ & $-0.023^{* * *}$ & $-0.023^{* * *}$ \\
\hline & $(0.004)$ & $(0.004)$ & $(0.004)$ & $(0.004)$ \\
\hline \multirow{2}{*}{ Whether having medical insurance } & $-0.043^{*}$ & $-0.044^{*}$ & $-0.044^{*}$ & $-0.044^{*}$ \\
\hline & $(0.025)$ & $(0.025)$ & $(0.025)$ & $(0.025)$ \\
\hline \multirow[b]{2}{*}{ Number of adult children } & -0.001 & -0.001 & -0.001 & -0.001 \\
\hline & $(0.004)$ & $(0.004)$ & $(0.004)$ & $(0.004)$ \\
\hline \multirow{2}{*}{ Living arrangement } & $-0.034^{* * *}$ & $-0.034^{* * *}$ & $-0.033^{* * *}$ & $-0.033^{* * *}$ \\
\hline & $(0.010)$ & $(0.010)$ & $(0.010)$ & $(0.010)$ \\
\hline \multirow{2}{*}{ Housing conditions } & $-0.003^{* * *}$ & $-0.003^{* *}$ & $-0.003^{* * *}$ & $-0.003^{* * *}$ \\
\hline & $(0.001)$ & $(0.001)$ & $(0.001)$ & $(0.001)$ \\
\hline \multirow{2}{*}{ Public facility's status of the community } & $0.019^{* * *}$ & $0.019^{* * *}$ & $0.019^{* * *}$ & $0.019^{* * *}$ \\
\hline & $(0.006)$ & $(0.006)$ & $(0.006)$ & $(0.006)$ \\
\hline \multirow{2}{*}{ Ecological environment of the community } & $0.030^{* * *}$ & $0.029^{* * *}$ & $0.030^{* * *}$ & $0.030^{* * *}$ \\
\hline & $(0.006)$ & $(0.006)$ & $(0.006)$ & $(0.006)$ \\
\hline \multirow{2}{*}{ Constant } & $2.488^{* * *}$ & $2.486^{* * *}$ & $2.482^{* * *}$ & $2.488^{* * *}$ \\
\hline & $(0.130)$ & $(0.130)$ & $(0.130)$ & $(0.130)$ \\
\hline Province fixed effect & Yes & Yes & Yes & Yes \\
\hline Breusch-Pagan test & $10.12^{* * *}$ & $10.29^{* * *}$ & $8.41^{* * *}$ & $8.41^{* * *}$ \\
\hline R-squared & 0.182 & 0.182 & 0.180 & 0.179 \\
\hline Observations & 3585 & 3585 & 3585 & 3585 \\
\hline
\end{tabular}

Notes: Robust standard errors are put into parentheses; ${ }^{* * *}$ indicates significance at $1 \%$ level, ${ }^{* *}$ at $5 \%$ level and ${ }^{*}$ at $10 \%$ level; For the row of Breusch-Pagan test, values are Chi squared statistics.

above. Similarly, the marginal effect size increases when the number of unmarried sons aged 28 years old and above is larger, showing a negative effect of the adult sons' marriage squeeze on parental mental health in rural China.

Heterogeneity of the association between adult sons' marriage squeeze and rural parent's mental health Investigating the heterogeneous associations between adult sons' marriage squeeze and rural parental mental health is beneficial to better understand the effects of the marriage squeeze in rural China. Therefore, we divide our sample into subgroups by parent's gender (fathers and mothers), parent's age $(<60$ years old and $>=60$ years old $)$ and parent's living arrangement (living with children and living alone or only living with the spouse). For conciseness, we only use the binary measure of adult sons' marriage squeeze in the following subgroup analyses. (Results with the integer measure of the number of unmarried adult sons aged 28 years old and above are similar and available from the authors upon request). The regression estimates of subgroup analyses are presented in table 3 . Results show a larger negative effect of the adult sons' marriage squeeze on the mental health of mothers than fathers. One possible reason is that mothers may be more likely to contact with their older unmarried sons than fathers, which makes mothers more vulnerable to the negative effects of their adult sons' marriage squeeze.

In terms of parent's age, the estimated coefficient is substantially larger for parents whose age 
Table 3 - Estimates of regression in subgroups.

\begin{tabular}{|c|c|c|c|c|c|c|}
\hline \multirow[t]{2}{*}{ Variables } & \multicolumn{2}{|c|}{----------Gender--------- } & \multicolumn{2}{|c|}{-----------------Age---------------- } & \multicolumn{2}{|c|}{-----------Living arrangement---------' } \\
\hline & Mothers & Fathers & $<60$ years old & $>=60$ years old & $\begin{array}{l}\text { Living with } \\
\text { children }\end{array}$ & $\begin{array}{l}\text { Living alone or living } \\
\text { with the spouse }\end{array}$ \\
\hline \multirow{2}{*}{$\begin{array}{l}\text { Whether having unmarried } \\
\text { sons aged } 28 \text { years old and } \\
\text { above }(1=\text { yes, } 0=\text { no })\end{array}$} & $0.070^{* * *}$ & $0.054^{* * *}$ & $0.093^{* * *}$ & $0.041^{* * *}$ & $0.065^{* * *}$ & $0.055^{* * *}$ \\
\hline & $(0.017)$ & $(0.018)$ & $(0.022)$ & $(0.016)$ & $(0.017)$ & $(0.019)$ \\
\hline \multirow{2}{*}{ Constant } & $2.431^{* * *}$ & $2.522^{* * *}$ & $2.769^{* * *}$ & $2.254^{* * *}$ & $2.414^{* * *}$ & $2.636^{* * *}$ \\
\hline & $(0.168)$ & $(0.180)$ & $(0.235)$ & $(0.131)$ & $(0.152)$ & $(0.101)$ \\
\hline Control variables & Yes & Yes & Yes & Yes & Yes & Yes \\
\hline Province fixed effect & Yes & Yes & Yes & Yes & Yes & Yes \\
\hline Breusch-Pagan test & 0.03 & $12.87^{* * *}$ & $6.41^{* *}$ & $6.65^{* * *}$ & $9.82^{* * *}$ & $2.75^{*}$ \\
\hline R-squared & 0.143 & 0.205 & 0.203 & 0.187 & 0.179 & 0.213 \\
\hline Observations & 1969 & 1616 & 1072 & 2513 & 2211 & 1374 \\
\hline
\end{tabular}

Notes: Robust standard errors are put into parentheses; ${ }^{* * *}$ indicates significance at $1 \%$ level, ${ }^{* *}$ at $5 \%$ level and ${ }^{*}$ at $10 \%$ level; For the row of Breusch-Pagan test, values are Chi squared statistics.

are less than 60 years old, indicating that middle-aged parents suffer more mental health losses than elderly parents caused by adult sons' marriage squeeze. This is possibly because middle-aged parents provide more intergenerational support for their unmarried sons than elderly parents. A large amount of downstream intergenerational transfers will increase the pressure and urgency of middle-aged parents and ultimately damage their mental health. In terms of parent's living arrangement, whether having unmarried adult sons aged 28 years old and above coefficient is significantly larger for parents living with children, showing that adult sons' marriage squeeze has a greater negative impact on the coresiding parents' mental health than parents living alone or only living with the spouse. The possible reason is similar to that of middle-aged parents who may provide more intergenerational support for their unmarried sons than parent living alone or living with the spouse.

As CESD score is continuous variable, we also use unconditional quantile regression to explore heterogeneity in the effect of adult sons' marriage squeeze on their rural parents with different mental health status. Table 4 presents the regression estimates of OLS regressions and quantile regressions from 10th quantile to 90th quantile of CESD score. Results in Table 4 shows that the effect size of whether having unmarried sons aged 28 years old and above is the least for rural parents with the poorest CESD score and the best CESD score, demonstrating that adult sons' marriage squeeze is less negative effective for those rural parents who have poorer or better mental health.

Table 4 - Estimates of quantile regression.

\begin{tabular}{|c|c|c|c|c|c|c|}
\hline Variables & OLS & Q10 & Q25 & Q50 & Q75 & Q90 \\
\hline \multirow{2}{*}{$\begin{array}{l}\text { Whether having unmarried sons aged } 28 \text { years old and above ( } 1 \\
=\text { yes, } 0=\text { no) }\end{array}$} & $0.061^{* * *}$ & $0.037^{*}$ & $0.063^{* * *}$ & $0.086^{* * *}$ & $0.072^{* * *}$ & $0.050^{* * * *}$ \\
\hline & $(0.013)$ & $(0.020)$ & $(0.020)$ & $(0.020)$ & $(0.016)$ & $(0.016)$ \\
\hline \multirow[t]{2}{*}{ Constant } & $2.488^{* * *}$ & $2.117^{* * *}$ & $2.250^{* * *}$ & $2.415^{* * *}$ & $2.792^{* * *}$ & $3.029^{* * *}$ \\
\hline & $(0.130)$ & $(0.188)$ & $(0.185)$ & $(0.194)$ & $(0.217)$ & $(0.223)$ \\
\hline Control variables & Yes & Yes & Yes & Yes & Yes & Yes \\
\hline Province fixed effect & Yes & Yes & Yes & Yes & Yes & Yes \\
\hline R-squared/Pseudo $\mathrm{R}^{2}$ & 0.182 & 0.076 & 0.100 & 0.107 & 0.111 & 0.121 \\
\hline Observations & 3585 & 3585 & 3585 & 3585 & 3585 & 3585 \\
\hline
\end{tabular}

Notes: Robust standard errors are put into parentheses; ${ }^{* * *}$ indicates significance at $1 \%$ level, ${ }^{* *}$ at $5 \%$ level and ${ }^{*}$ at $10 \%$ level. 
The mechanism of the association between adult sons' marriage squeeze and rural parent's mental health

The previous sections have shown a significant and negative association between adult sons' marriage squeeze and rural parental mental health. But how does this association arise? In this section, we apply a stepwise approach to identify the mechanisms of the effect, which consists of two steps: firstly, we examine the effects of adult sons' marriage squeeze on possible intermediate factors which may affect rural parents' mental health; secondly, we include intermediate factors that are significant in the first step as independent variables alongside adult sons' marriage squeeze measure in modelling parental mental health outcomes. If intermediate factors in the second step are significantly associated with parental mental health outcomes and the positive coefficient of whether having unmarried adult sons aged 28 years old and above is reduced in the estimation, then we argue that these factors are the mediators between adult sons' marriage squeeze and rural parental mental health.

Previous studies have demonstrated that adult children's marriage can affect parent's mental health in the following ways. Firstly, the burden of parents providing intergenerational support for their children will increase as adult children's marriage squeezes becomes more serious (JIN et al., 2015; CHEN, 2018). For example, evidence from Northwestern Shanxi province in China showed that the rigid demand for rural males' marriages made it necessary for rural parents to continuously transfer resources to their offspring families (CHEN, 2018). Secondly, adult children's marriage squeeze may aggravate the intergenerational relationship between parents and their adult children, which can directly affect parent's mental health. For instance, a part of older unmarried children often blame their failure to get married on their parents (MO, 2005a), resulting in particularly tense intergenerational relationships. And another part of unmarried adult children often quarrels with their parents because of marriage problems. Thirdly, adult children's marriage squeeze may influence parental mental health through neighborhood relationship. Since rural China residents often take children's better marriage as honors, when parents are unable to complete their child's marriage responsibilities, they are often discriminated against by their neighbors (LI \& LI, 2008).

Therefore, we examine three possible channels through which adult sons' marriage squeeze affects parents' mental health in rural China: intergenerational support, intergenerational relationship and neighborhood relationship. Firstly, we generate one binary variables regarding intergenerational support from CFPS questionnaires: whether providing downstream intergenerational financial transfers in the past 6 months. If a rural parent provide intergenerational financial support for at least one unmarried adult son aged 28 years old and over, the assignment is 1; otherwise, the assignment is 0 . Secondly, relationship with adult sons aged 28 years old and above in the past 6 months $(1=$ not close at all, $2=$ not very close, $3=$ Fair, $4=$ Close, $5=$ very close) is used to measure the intergenerational relationship between older unmarried sons and their rural parents. Thirdly, thinking the neighborhood is not friendly to rural parent $(1=$ nearly, $2=$ sometimes, $3=$ often, $4=$ most of the time) is as the substitute variable for neighborhood relationship. The OLS regression models are used to estimate these relationships, and all estimates results are reported in table 5 and table 6 .

Table 5 presents results of the relationships between adult sons' marriage squeeze and intergenerational support, intergenerational relationship and neighborhood relationship. The results show that whether having unmarried sons aged 28 years old and above is significantly positively associated with whether providing downstream intergenerational financial transfers, showing that adult sons' marriage squeeze has a positive effect on parent's downstream transfers for their older unmarried sons. On average, rural parents with unmarried sons aged 28 years old and over are 7.6 percent more likely to provide financial transfers in the past 6 months than recipients without unmarried sons aged 28 years old and above. In terms of intergenerational relationship, a significant and negative association between adult sons' marriage squeeze and rural parent's relationship is reported. Specifically, the rural parents with unmarried sons aged 28 years and over have a $31.8 \%$ worse relationship with their adult children than the rural parents without unmarried sons aged 28 years and above in the past 6 months. In addition, our findings also report that adult sons' marriage squeeze has a negative impact on neighborhood relationship. Specifically, rural parents who have unmarried sons aged 28 years old and above are $27.1 \%$ more likely to be treated unfriendly by their neighbors than those who do not have unmarried sons aged 28 years old and above.

After establishing significant associations between adult sons' marriage squeeze and intergenerational support, intergenerational relationship and neighborhood relationship, we 
Table 5 - Channels of adult sons' marriage squeeze effect on rural parent's mental health.

\begin{tabular}{lccc}
\hline Variables & $\begin{array}{c}\text { Whether providing downstream } \\
\text { intergenerational financial } \\
\text { transfers }\end{array}$ & $\begin{array}{c}\text { Relationship with adult sons } \\
\text { aged 28 years old and above }\end{array}$ & $\begin{array}{c}\text { Thinking the neighborhood } \\
\text { is not friendly to rural parent }\end{array}$ \\
\hline $\begin{array}{l}\text { Whether having unmarried adult } \\
\text { sons aged 28 years old and above } \\
(1=\text { yes, } 0=\text { no) }\end{array}$ & $0.076^{*}$ & $-0.318^{* * *}$ & $(0.116)$ \\
Constant & $(0.042)$ & $3.950^{* * *}$ & $(0.100)$ \\
Control variables & 0.267 & $(0.708)$ & $2.674^{* * *}$ \\
Province fixed effect & $(0.226)$ & Yes & $(0.609)$ \\
Breusch-Pagan test & Yes & $37.19^{* * *}$ & Yes \\
R-squared & Yes & 0.141 & $99.85^{* * *}$ \\
Observations & $102.04^{* * *}$ & 541 & 0.129 \\
\hline
\end{tabular}

Notes: Robust standard errors are put into parentheses; ${ }^{* * *}$ indicates significance at $1 \%$ level, ${ }^{* *}$ at $5 \%$ level and ${ }^{*}$ at $10 \%$ level; For the row of Breusch-Pagan test, values are Chi squared statistics.

extend the model of adult sons' marriage squeeze and rural parent's mental health with the inclusion of significant intermediate factors in step one (Table 6). The estimates show that the coefficient of whether having unmarried sons aged 28 years old and above decreases with the inclusion of whether providing downstream intergenerational financial transfers, which is significantly and positively associated with CESD score of rural parents, indicating that intergenerational support is one channel through which adult sons' marriage squeeze affect rural parent's mental health. Further, our findings also report that intergenerational relationship and neighborhood relationship are significantly correlated with rural parent's mental health outcomes, displaying that intergenerational relationship and

Table 6 - Expanded model of adult sons' marriage squeeze and rural parent's mental health.

\begin{tabular}{|c|c|c|c|c|c|}
\hline Variables & (1) & (2) & (3) & (4) & (5) \\
\hline \multirow{2}{*}{$\begin{array}{l}\text { Whether having unmarried adult sons aged } 28 \text { years old and } \\
\text { above }\end{array}$} & $0.097^{* * *}$ & $0.089^{* *}$ & $0.079^{* *}$ & $0.060^{*}$ & 0.044 \\
\hline & $(0.036)$ & $(0.035)$ & $(0.035)$ & $(0.033)$ & $(0.032)$ \\
\hline \multirow{2}{*}{$\begin{array}{l}\text { Whether providing downstream intergenerational financial } \\
\text { transfers }\end{array}$} & & $0.102^{* *}$ & & & $0.072^{*}$ \\
\hline & & $(0.046)$ & & & $(0.043)$ \\
\hline \multirow{2}{*}{ Relationship with adult sons aged 28 years old and above } & & & $-0.054^{* * *}$ & & $-0.037^{* *}$ \\
\hline & & & $(0.017)$ & & $(0.015)$ \\
\hline \multirow{2}{*}{ Thinking the neighborhood is not friendly to rural parent } & & & & $0.136^{* * *}$ & $0.130^{* * *}$ \\
\hline & & & & $(0.019)$ & $(0.019)$ \\
\hline \multirow{2}{*}{ Constant } & $2.909^{* * *}$ & $2.881^{* * *}$ & $3.122^{* * *}$ & $2.546^{* * *}$ & $2.688^{* * *}$ \\
\hline & $(0.228)$ & $(0.227)$ & $(0.225)$ & $(0.199)$ & $(0.205)$ \\
\hline Control variables & Yes & Yes & Yes & Yes & Yes \\
\hline Province fixed effect & Yes & Yes & Yes & Yes & Yes \\
\hline Breusch-Pagan test & 1.95 & 2.19 & 0.60 & 0.19 & 0.00 \\
\hline R-squared & 0.222 & 0.232 & 0.240 & 0.314 & 0.329 \\
\hline Observations & 541 & 541 & 541 & 541 & 541 \\
\hline
\end{tabular}

Notes: Robust standard errors are put into parentheses; ${ }^{* * *}$ indicates significance at $1 \%$ level, ${ }^{* *}$ at $5 \%$ level and ${ }^{*}$ at $10 \%$ level; For the row of Breusch-Pagan test, values are Chi squared statistics.

Ciência Rural, v.50, n.2, 2020. 
neighborhood relationship are the other two channels that adult sons' marriage squeeze affect rural parental mental health. To sum up, our analyses indicat that intergenerational support, intergenerational relationship and neighborhood relationship are the main channels between adult sons' marriage squeeze and their parent's mental health in rural China. More intuitively, the adult sons' marriage squeeze mainly damages the mental health of rural parents by increasing the downstream intergenerational support of rural parents and worsening intergenerational and neighborhood relationships.

\section{Robustness checks}

In the previous study; although, we use adult sons' marriage squeeze in 2014 to solve the causal problem between adult sons' marriage squeeze and rural parent's mental health, and we also control a set of variables that may correlate with rural parent's mental health, we still need to consider potential endogeneity caused by other reason. Conversely, family structure may simultaneously affect adult sons' marriage squeeze and rural parent's mental health. It is possible that rural parents with only one child are more likely to realize early marriage of their child, but have less current knowledge about good care practices for rural parents. Conversely, some other invisible factors in rural China, which may also be correlated to adult sons' marriage squeeze and affect the mental health status of parents.

In order to address these problems, we apply two approaches to check the robustness of our findings. Firstly, we divide our sample into subgroups by children size of rural family (one child families and two children families). And then estimating the relationship between adult sons' marriage squeeze and the mental health of their parents in rural one-child families and rural two-children families, respectively. Table 7 presents OLS coefficient estimates of adult sons' marriage squeeze on parental mental health from one child families and two children families. And from table 7, we can see that whether having unmarried sons aged 28 years old and above in one child and two children families has a significant positive impact on parents' CESD score, indicating that the impact of adult sons' marriage squeeze on rural parent's mental health does not differ according to the size of children.

Secondly, we further employ two stage least square (2SLS) regression with instrumental variable (IV) to address the potential endogeneity in our analysis (The proportion of families with unmarried sons aged 28 years old and above in the community as instrumental variable). For the first stage estimation, Breusch-Pagan test is performed to test for heteroscedasticity, result of which shows that there is heteroscedasticity in the first stage estimation model. In order to cope with the heteroscedasticity issue, robust standard errors are applied, which are shown in the parentheses. The Wu-Hausman test in table 8 indicates that "Whether having unmarried sons aged 28 years old and above" is endogenous to rural parental mental health outcomes $(\mathrm{p}<0.05)$, thus supporting our approach. Our test of instrument relevance - the strength of our instrument -is based on the Wald F-statistics based on the Kleibergen-Paap statistic, to allow for the presence of non-independent and identically distributed (non-i.i.d) errors arising

Table 7 - Effect of adult sons' marriage squeeze on their rural parental mental health in one child families and two-children families.

\begin{tabular}{lcc}
\hline Variables & One child families & Two children families \\
\hline $\begin{array}{l}\text { Whether having unmarried sons aged 28 years old } \\
\text { and above }(1=\text { yes, } 0=\text { no) }\end{array}$ & $0.062^{* * *}$ & $0.091^{* * *}$ \\
Constant & $(0.017)$ & $(0.022)$ \\
Control variables & $2.422^{* * *}$ & $2.574^{* * *}$ \\
Province fixed effect & $(0.188)$ & $(0.181)$ \\
Breusch-Pagan test & Yes & Yes \\
R-squared & Yes & Yes \\
Observations & $5.41^{* *}$ & 1.40 \\
& 0.201 & 0.190 \\
\hline
\end{tabular}

Notes: Robust standard errors are put into parentheses; ${ }^{* * *}$ indicates significance at $1 \%$ level, ${ }^{* *}$ at $5 \%$ level and ${ }^{*}$ at $10 \%$ level; For the row of Breusch-Pagan test, values are Chi squared statistics. 
Table 8 - Effect of adult sons' marriage squeeze on their rural parental mental health - IV Estimation Results.

\begin{tabular}{|c|c|c|}
\hline & The first stage & The second stage \\
\hline \multirow{2}{*}{$\begin{array}{l}\text { Whether having unmarried sons aged } 28 \text { years old } \\
\text { and above }(1=\text { yes, } 0=\text { no })\end{array}$} & & $0.109^{* * *}$ \\
\hline & & $(0.025)$ \\
\hline \multirow{2}{*}{$\begin{array}{l}\text { Whether having unmarried sons aged } 28 \text { years old } \\
\text { and above in the community }\end{array}$} & $0.994^{* * *}$ & \\
\hline & $(0.030)$ & \\
\hline \multirow{2}{*}{ Constant } & $2.235^{* * *}$ & $2.474^{* * *}$ \\
\hline & $(0.078)$ & $(0.130)$ \\
\hline Control variables & Yes & Yes \\
\hline Province fixed effect & Yes & Yes \\
\hline $\mathrm{N}$ & 3585 & 3585 \\
\hline Breusch-Pagan test & $854.10^{* * *}$ & \\
\hline Kleibergen-Paap rk Wald F statistic & 1100.068 & \\
\hline Wu-Hausman test (P value) & 0.029 & \\
\hline
\end{tabular}

Notes: Robust standard errors are put into parentheses; ${ }^{* * *}$ indicates significance at $1 \%$ level, ${ }^{* *}$ at $5 \%$ level and ${ }^{*}$ at $10 \%$ level; For the row of Breusch-Pagan test, values are Chi squared statistics.

from arbitrary heteroscedasticity. The Wald F-statistic is 1100.068 , which exceeds proposed limits for what would be considered a weak instrument. Namely, the instrument chosen is not a weak instrument. From the regression results of the second stage, we can see that after overcoming the potential endogeneity in the OLS regression process, adult sons' marriage squeeze still has a significant negative impact on their rural parental mental health.

\section{DISCUSSION AND CONCLUSION}

This paper contributed to research on the effect of adult sons' marriage squeeze on parent's mental health in rural China by using data from China Family Panel Studies. We not only investigated the association between adult sons' marriage squeeze and rural parental mental health, but also analyzed the heterogeneity and possible channels of the effect, and discussed and tested the possible endogeneity problem. Results of our study showed that rural parents with unmarried sons aged 28 years old and above are significantly associated with worse mental health status. We also reported that the association is larger for rural mothers, parents whose age are less 60 years old, and parents living with children. The estimates of quantile regression demonstrated that the relationship is heterogeneous across the distribution of parent's mental health and adult sons' marriage squeeze is less negative effective for those rural parents who have poorer or better mental health.
For the channels through which adult sons' marriage squeeze affects rural parent's mental health, we tested mechanisms, including intergenerational support, intergenerational relationship, and neighborhood relationship, and reported that adult sons' marriage squeeze mainly damages the mental health of rural parents by increasing the downstream intergenerational support of rural parents and worsening intergenerational and neighborhood relationships. Considering possible endogeneity problems, a sample of one-child families and two-children families, IV estimation approach were adopted to check the robustness of the results and finally the estimates were consistent with OLS regressions.

Although, no previous studies have comprehensively examined the relationship between adult sons' marriage squeeze and their parent's mental health in rural China, our findings are supported by the international literature. For example, a study conducted from MO (2005b) has shown that when parents are unable to fulfill their responsibilities for getting children's marriage, anxiety, guilt, selfblame and external public opinion will put a huge psychological burden on them (MO, 2005b). In addition, another study from Henan province in China reported that the existence of older unmarried men will increase the mental stress of their parents and damage their parent's psychological wellbeing (LI \& LI, 2008). Findings from other countries on the relationship between adult children's marriage squeeze and parental well-being also supported the findings of our research. Research conducted in 
Korean has reported that adult children's marriagedelay are associated with loss of parents' life satisfaction and increase levels of depression (LEE \& JUN, 2017). It has also been found in a Netherlands' sample that a child's divorce will lead to a decline in parental well-being (KALMIJN \& GRAAF, 2012).

Our findings have several implications for the evaluation of marriage squeeze and resident's health protection. Firstly, this paper confirms that adult sons' marriage squeeze has a negative impact on the mental health of rural parents, which suggests that we should not only pay attention to the situation of the middle aged and elderly people themselves in rural areas, but also pay attention to the role played by family members and traditional culture when we plan to improve the mental health of middleaged and elderly rural people. Secondly, this paper further shows that rural parents with older adult sons unmarried are more prone to provide more downstream intergenerational transfers, have a bad relationship with their older adult sons who have not married and face discrimination in the neighborhood. These findings are important because they have allowed us to identify the mechanism determination of rural parent's mental health in China. With this knowledge, it will be possible to develop policies and programs targeting these subjects who with older adult sons unmarried that can improve their well-being and reduce the unmarried rate of adult children across China. Thirdly, this paper also shows that marriage squeeze is seriously harmful, because marriage squeeze can not only cause the loss of the wellbeing of the squeezed individual, but also cause the loss of the wellbeing of other people. When evaluating the effect of marriage squeeze, most previous studies only paid attention to the well-being of the subjects facing a marriage squeeze, but ignored the effect on the wellbeing of other people, especially on their family members. Therefore, the evaluation effect of marriage squeeze may be underestimated, which may directly negatively affect the introduction of the corresponding policy. From a policy perspective, our results suggest that the universality of adult sons' marriage squeeze in rural China must not be ignored. The Chinese government should fully recognize the seriousness of older men in rural areas who are unmarried.

Despite the contributions and policy implications to development studies, it warrants mentioning the limitations of the present study. Firstly, most of the items used to form the CESD index have many missing values, so that our CESD index only include 8 items. The simplified CESD profile may not be a good measure of the mental health of China's rural parents. Secondly, adult sons' marriage squeeze includes multi-dimensional content, and our key variables-whether having unmarried adult sons aged 28 years old and above may not fully represent adult sons' marriage squeeze. Meanwhile, due to data limitations, we cannot rule out the existence of voluntary single phenomenon when taking whether having unmarried adult sons aged 28 years old and over as adult sons' marriage squeeze variable. Thirdly, the influence of adult sons' marriage squeeze on parent's mental health may not be limited to intergenerational support, intergenerational relationship and neighborhood relationship, so there may be still many mechanisms that we have not tested.

\section{ACKNOWLEDGEMENTS}

We would like to thank two anonymous reviewers and the editor of this journal for their useful comments and suggestions. This work was fnancially supported by the National Social Science Foundation of China (19BMZ116).

\section{DECLARATION OF CONFLICT OF INTERESTS}

The authors declared no potential conflicts of interest with respect to the research, authorship, and/or publication of this article.

\section{AUTHORS' CONTRIBUTIONS}

Guangyan Chen was fully engaged in writing the manuscript and was also fully involved in paper revision. Lingling Qiu performed data analysis and was involved in paper revision. Wei Si provided supervision and support for the completion of the paper.

\section{REFERENCES}

CHEN, X. Marriage price, intergenerational support and urbanization of rural youth -- based on a survey of W village in northwest Shanxi Province [J]. China youth research, n.2, p.1823+119, 2018. (In Chinese).

CHEN, H. F.; CHEN, H. S. A cohort study of the influence of marital status on negative emotions in the elderly. Chinese Mental Health Journal, v.26, n.2, p.104-110, 2012. (In Chinese).

GAO, J. J. et al. Influence of depression tendency on labor participation of middle-aged and elderly people in China -an empirical analysis based on CHARLS panel data. Labor economics research, v.6, n.1, p.63-80, 2018. (in Chinese).

GUO, W. et al. Economic Status, Family Dependence, and Health Outcomes of Older People in Western Rural China. Journal of gerontological social work, n.10, p.762-775, 2019. Available from: <https://www.tandfonline.com/doi/full/10.1 080/01634372.2019.1676860>. Accessed: Oct. 9, 2019. doi: 10.1080/01634372.2019.1676860. 
GUO, Q. J.; JIN, X. Y. Research on Life Satisfaction of Parents under the Background of Marriage Squeeze_-Based on the Sample Survey in Yi county rural areas, Anhui Province. China rural survey, n.6, p.62-70, 2012. (In Chinese).

JIN, X. Y. et al. Marriage Squeeze and Intergenerational Support in Contemporary Rural China: Evidence from X County of Anhui Province. International Journal Of Aging \& Human Development, v.80, n.2, p.115-139, 2015. Available from: $<\mathrm{https}$ :// journals.sagepub.com/doi/abs/10.1177/0091415015590304>. Accessed: Jan. 1, 2015. doi: 10.1177/0091415015590304.

KALMIJN, M.; GRAAF, P. M. D. Life Course Changes of Children and Well-being of Parents. Journal of Marriage and Family, v.74, n.2, p.269-280, 2012. Available from: <https://onlinelibrary.wiley. com/doi/full/10.1111/j.1741-3737.2012.00961.x>. Accessed: Mar. 19, 2012. doi: 10.1111/j.1741-3737.2012.00961.x.

LEE, S. M.; JUN, H. J. The effects of adult children's marriage-delay on parents' mental health. Journal of Family Relations, v.22, n.3, p.131-153, 2017. Available from: <http://kiss.kstudy.com/thesis/thesisview.asp? $\mathrm{g}=$ kissmeta\&m $=$ exp\&enc $=168707 \mathrm{C} 858032 \mathrm{~A} 927 \mathrm{CB} 1 \mathrm{~A}$ EA055948131>. Accessed: Oct. 1, 2017. doi: 10.21321/jfr.22.3.131.

LI, Y.; LI, S. Z. The pressure and response of the older unmarried young men in rural China. Youth Research, n.11, p.15-23, 2008. (In Chinese)

LI, Z. B. et al. Obesity and depressive symptoms in Chinese elderly. International Journal of Geriatric Psychiatry, v.19, n.1, p.68-74 2004. Available from: $<$ https://onlinelibrary.wiley.com/doi/abs/10.1002/ gps.1040>. Accessed: Jan. 5, 2004. doi: 10.1002/gps.1040.

LIAO, S. H.; SONG, C. L. The Labor Supply of the Elderly in Rural of China: Evidence from Shandong Province in China. Population and economy, n.2, p.60-68, 2013. (in Chinese).

LIU, B. P. et al. Suicide attempters with high and low suicide intent: Different populations in rural China. Psychiatry Research, v.251, n.5, p.176-181, 2017. Available from: < https://www.sciencedirect. com/science/article/pii/S0165178116308873?via\%3Dihub $>$. Accessed: Feb. 8, 2017. doi: 10.1016/j.psychres.2017.01.096.

MO, L. Research on the Consequences of Abnormally High Sex Ratio at Birth. Beijing: China Population Press, 2005a. (In Chinese).

MO, L. A Study on the Consequences of Increasing Sex Ratio at Birth. Beijing: China Population Press, 2005b. (In Chinese).

REN, G. Q. et al. The Impact of Income, Individual Income Deprivation on Health of Urban and Rural Residents in China: An Analysis Based on CGSS2010. Nankai Economic Studies, n.6, p.3-22, 2016. (In Chinese).
SUN, S. M. The Peasant's Choice of Spouse--An Empirical Study of Zhaocun in Northwest China. Social Science Literature Publishing House, 2005. (In Chinese).

TAO, Y. C.; SHEN, W. The Influence of Social Support on the Physical and Mental Health of Rural Elderly. Population and Economy, n.3, p.3-14, 2014. (In Chinese).

WEI, Y.; ZHANG, L. The marriage dilemma of involuntary bachelors in Rural China: From the perspective of gender inequality. Population Research, n.5, p.58-70, 2011. (In Chinese).

XIAO, C. et al. Differences of schizophrenia-induced family burden of between rural and urban areas in China: a meta-analysis. Modern Preventive Medicine, v.43, n.3, p.498-502, 2016. (in Chinese).

XIE, Y. China family panel studies, user's manual for the 2010 baseline survey. Beijing: Peking University Institute of Social Science Survey, 2012. (In Chinese)

XU, H. W. Physical and mental health of Chinese grandparents caring for grandchildren and great-grandparents. Social Science \& Medicine, n.S1, p.106-116, 2018. Available from: <https:// www.sciencedirect.com/science/article/pii/S0277953618302909>. Accessed: May, 26, 2018. doi: 10.1016/j.socscimed.2018.05.047.

YE, M. Z.; CHEN, Y. W. The influence of domestic living arrangement and neighborhood identity on mental health among urban Chinese elders. Aging \& Mental Health, v.18, n.1, p.40-50, 2014. Available from: <https://www.ncbi.nlm. nih.gov/pubmed/24044640>. Accessed: Sep. 17, 2013. doi: 10.1080/13607863.2013.837142.

YIN, Q. et al. An investigation of physical and mental health consequences among Chinese parents who lost their only child. Bmc Psychiatry, v.18, n.1, p.45, 2018. Available from: $<$ https://bmcpsychiatry.biomedcentral.com/articles/10.1186/ s12888-018-1621-2>. Accessed: Feb. 12, 2018. doi: 10.1186/ s12888-018-1621-2.

ZHANG, Y. Y.; LI, J. X. The level of disability and mental health in the elderly: age difference and the regulation of community resources. Xue Hai, n.4, p.65-72, 2018. (In Chinese).

ZHANG, L. et al. Relationship between body mass index and depressive symptoms: the "fat and jolly" hypothesis for the middle-aged and elderly in China. Bmc Public Health, v.16, n.1, p.1201, 2016.

ZHOU, Q. et al. The Effect of Social Insurance on Mental Health among Rural Residence: An Empirical Analysis Based on CHARLS Data. China Economic Studies, n.5, p.125-136, 2018. (In Chinese). 